\title{
C-Src-mediated RANKL-induced breast cancer cell migration by activation of the ERK and Akt pathway
}

\author{
LINGYUN ZHANG $^{1 *}$, YUEE TENG $^{1 *}$, YE ZHANG ${ }^{1}$, JING LIU $^{1}$, LING XU $^{1}$, JINGLEI QU $^{1}$, \\ KEZUO HOU $^{1}$, XIANGHONG YANG ${ }^{2}$, YUNPENG LIU ${ }^{1}$ and XIUJUAN QU ${ }^{1}$ \\ ${ }^{1}$ Department of Medical Oncology, the First Hospital of China Medical University; \\ ${ }^{2}$ Department of Pathology, Shengjing Hospital of China Medical University, Shenyang 110001, P.R. China
}

Received June 21, 2011; Accepted October 31, 2011

DOI: $10.3892 / \mathrm{ol} .2011 .487$

\begin{abstract}
The receptor activator for nuclear factor $\mathrm{\kappa B}$ ligand/ receptor activator for nuclear factor $\kappa \mathrm{B}$ (RANKL/RANK) pathway is critical for RANK-expressing cancer cells to home to bones, and c-Src is critical for cancer progression. The objective of this study was to explore the effect of c-Src in the RANKL/RANK pathway and migration activity in human breast cancer cells. Breast cancer cell lines MCF-7, MDA-MB-231 and BT-474 were obtained and cultured. Flow cytometry was used to examine RANK expression. The results showed that RANK was expressed in breast cancer cell lines MCF-7, MDA-MB-231 and BT-474, and soluble RANKL (sRANKL)-triggered migration of breast cancer cells by activating ERK1/2, Akt and c-Src. The sRANKL-induced migration was blocked with RANKL inhibitor osteoprotegerin (OPG), MEK inhibitor PD98059, PI3K inhibitor LY294002 and Src inhibitor PP2. Inhibition of c-Src function with PP2 blocked the activation of Akt and ERK1/2, resulting in the inhibition of RANKL-induced migration. In conclusion, RANKL was found to increase the migration of breast cancer cells by activating the c-Src-Akt and c-Src-ERK signaling pathways.
\end{abstract}

\section{Introduction}

Breast cancer is the most common cancer among women, and is second only to lung cancer as the leading cause of cancer mortality (1). Although early stage breast cancer is not life threatening, development of metastatic breast cancer

Correspondence to: Dr Xiujuan $\mathrm{Qu}$ and Dr Yunpeng Liu, Department of Medical Oncology, the First Hospital of China Medical University, No. 155, North Nanjing Street, Heping, Shenyang 110001, P.R. China

E-mail: xiujuanqu@yahoo.com

E-mail: cmuliuyunpeng@yahoo.cn

\section{${ }^{*}$ Contributed equally}

Key words: c-Src, receptor activator for nuclear factor $\kappa \mathrm{B}$ ligand, migration, breast cancer is responsible for the majority of cancer-related mortality. Advanced breast cancer commonly spreads to the bones, lungs, liver or brain, with bone being the most common site of breast cancer metastasis. Almost all patients with advanced breast cancer finally develop bone metastasis and suffer from serious bone metastases-associated complications. Therefore, understanding the mechanisms that facilitate bone metastasis is of great importance.

For the past decade, chemokine pathways, such as SDF-1/ CXCR4 and CCL21/CCR7, were thought to play a significant role in breast cancer distant metastasis $(2,3)$. However, it was shown that inhibition of these pathways in vivo only partially blocks metastatic behavior (2-4), indicating that other factors exist that regulate the metastasis of breast cancer cells. Receptor activator of NF- $\mathrm{KB}$ ligand (RANKL) is a member of the tumor necrosis factor family of cytokines and its receptor, receptor activator of NF- $\mathrm{kB}$ (RANK), is primarily expressed on osteoclasts. Previous studies showed that RANKL binds to RANK or the decoy receptor osteoprotegrein (OPG) (5) to modulate osteoclast differentiation, activation and survival (6-11). RANK is reportedly expressed in certain cancer cells, and the RANKL/RANK pathway induces the migration of prostate, renal, lung and human breast cancer cells, T47D (4,12-15). Furthermore, the RANKL/RANK pathway has been shown to trigger the bone-specific migration of RANK-expressing mouse malignant melanoma and human prostate cancer cells $(4,13)$. However, the RANKL-mediated signaling pathways in breast cancer cells are not well understood.

The non-receptor tyrosine kinase c-Src, a significant molecule in cell migration, adhesion and osteoclast-mediated bone resorption (16-18), is also over-expressed and activated in a large number of human malignancies, and the correlation between c-Src activation and cancer progression appears to be significant (18). c-Src is reportedly involved in RANKLinduced prostate cancer cell migration (19) and promotes lung and latent breast cancer bone metastasis $(20,21)$. However, the effect of c-Src on the RANKL/RANK pathway and migration activity in human breast cancer cells remains unknown.

In this study, we described a phenomenon whereby the RANKL and RANK interaction increased the migration of three representative human breast cancer cell lines, MCF-7 $\left(\mathrm{ER} / \mathrm{PR}^{+}\right.$, Her-2), MDA-MB-231 (ER/PR', Her-2) and BT-474 $\left(\mathrm{ER} / \mathrm{PR}^{+}, \mathrm{Her}-2^{+}\right)$cells. In addition, we aimed to show that 
active c-Src mediates RANKL-induced breast cancer cell migration by activating the Akt and ERK pathways, c-Src and PP2 inhibitors and blocking the activation of Akt and ERK1/2, thereby inhibiting RANKL-induced migration.

\section{Materials and methods}

Cell culture. Breast cancer cell lines were obtained from the Type Culture Collection of the Chinese Academy of Sciences (Shanghai, China). MCF-7 and BT-474 were cultured in RPMI-1640 (Gibco; Invitrogen, CA, USA) containing 10\% fetal bovine serum (FBS), and MDA-MB-231 cells grown in Leibovitz L-15 medium (Gibco) containing 10\% FBS, according to the manufacturer's instructions.

Reagents and antibodies. Recombinant SRANKL and recombinant human OPG (rOPG) were purchased from Cytolab/ Peprotech Asia (NJ, USA). The specific PI3K inhibitor, LY294002, and Src inhibitor, PP2, were obtained from Sigma (St. Louis, MO, USA). Rabbit anti-RANK (used for immunohistochemistry), mouse anti-c-Src and rabbit anti- $\beta$-actin antibodies were obtained from Santa Cruz Biotechnology (Santa Cruz, CA, USA). Rabbit anti-Akt, anti-p-Akt (Ser473), anti-ERK1/2, anti-p-ERK1/2 (Thr202/Tyr204) and anti-p-Src (Y416) antibodies were obtained from Cell Signaling Technology (Danvers, MA, USA).

RANK expression analysis. Surface RANK expression was determined by flow cytometry following incubation with $25 \mu \mathrm{g}$ per $1 \times 10^{6}$ cells mouse anti-RANK antibody (R\&D) or isotype control (R\&D) followed by FITC-conjugated antimouse secondary antibody. Fluorescence was assessed using a FAScan sorter (BD Biosciences, NJ, USA).

Western blotting. To prepare total cell lysates, cell pellets were washed twice with ice-cold phosphate-buffered saline (PBS) and solubilized in 1\% Triton lysis buffer [1\% Triton $\mathrm{X}-100,50 \mathrm{mM}$ Tris- $\mathrm{HCl}$ (pH 7.4), $150 \mathrm{mM} \mathrm{NaCl}, 10 \mathrm{mM}$ EDTA, $100 \mathrm{mM} \mathrm{NaF}, 1 \mathrm{mM} \mathrm{Na} \mathrm{VO}_{4}, 1 \mathrm{mM}$ phenylmethylsulfonyl fluoride and $2 \mu \mathrm{g} / \mathrm{ml}$ aprotinin] on ice. Cell lysates were centrifuged at $12,000 \mathrm{x} \mathrm{g}$ for $30 \mathrm{~min}$ at $4^{\circ} \mathrm{C}$ and the supernatants were separated. Proteins were eluted by heat treatment at $100^{\circ} \mathrm{C}$ for 5 min with $3 \mathrm{X}$ sampling buffer. Total proteins $(30-50 \mu \mathrm{g})$ were subjected to SDS-polyacrylamide gel electrophoresis (SDS-PAGE) and electronically transferred to nitrocellulose membranes. After blocking with 5\% skimmed milk in $10 \mathrm{mM}$ Tris, $\mathrm{pH} 7.4,150 \mathrm{mM} \mathrm{NaCl}$ and $0.1 \%$ Tween 20 (TBST), the blots were probed with the indicated primary antibodies at $4^{\circ} \mathrm{C}$ overnight, followed by the horseradish peroxidase-conjugated specific goat anti-mouse or goat anti-rabbit secondary antibody, as indicated for $30 \mathrm{~min}$ at room temperature. Finally, proteins were detected using an enhanced chemiluminescence reagent (SuperSignal Western Pico Chemilunescent Substrate; Pierce, IL, USA) and visualized with the Electrophoresis Gel Imaging Analysis System (DNR Bio-Imaging Systems, Israel).

Transwell migration assay. Cells were washed twice in culture medium with $0.1 \%$ bovine serum albumin. A 24-well chemotaxis chamber $(8-\mu \mathrm{m}$ pore size; Corning; NY, USA) was used for this experiment. Prior to performing the migration assay, cells were pretreated with different concentrations of inhibitors or the appropriate solvent control [dimethyl sulfoxide (DMSO)] for $60 \mathrm{~min}$. A volume of $200 \mu \mathrm{l}\left(2 \times 10^{5}\right.$ cells $/ \mathrm{ml}$ ) from each sample was loaded onto the upper well. The medium $(0.5 \mathrm{ml})$ containing sRANKL, with or without the respective inhibitors or DMSO, was added to the bottom well. The plates were incubated for $16 \mathrm{~h}$ at $37^{\circ} \mathrm{C}$. Following incubation, the porous inserts were carefully removed and the cells on the lower surface of the membrane were stained and counted in at least five different fields. The results were expressed as the percentage of migrated cells as compared to the control (untreated) cells. Each experiment was performed three times and in triplicate.

Statistical analysis. Experimental data are expressed as the mean \pm standard deviation. The significance of the difference between the groups was assessed by the Student's two-tailed t-test, and $\mathrm{P}<0.05$ was considered significant in all statistical analyses. The mean values were calculated from at least three independent experiments. Statistical analyses were carried out using the statistical package software (SPSS for Windows, Version16.0; IBM, NY, USA).

\section{Results}

Breast cancer cells expressed RANK on their cell surface. Flow cytometry was used to examine RANK expression in the breast cancer cells. Three representative cell lines, MCF-7 (ER/PR ${ }^{+}$, Her-2), MDA-MB-231 (ER/PR', Her-2) and BT-474 cells $\left(\mathrm{ER} / \mathrm{PR}^{+}, \mathrm{Her}-2^{+}\right)(22,23)$ were selected to detect RANK expression. The result showed that all three cell lines expressed RANK on the cell surface (Fig. 1).

RANKL- and RANK interaction-directed migration of breast cancer cells. Stimulation of the MCF-7 cells by sRANKL at a concentration of $2 \mu \mathrm{g} / \mathrm{ml}$ significantly induced increased migration. Pretreatment of cells with OPG reduced RANKLinduced cell migration (Fig. 2A). Furthermore, we confirmed that RANKL has no mitogenic effect on MCF-7 cells (data not shown). Therefore, the increased number of cells traversing the filter was due to migration.

Similarly, RANKL also increased the migration of MDA-MB-231 and BT-474 cells, and RANKL-induced cell migration was blocked with OPG (Fig. 2B). Therefore, the RANKL and RANK interaction plays a significant role in the migration of human breast cancer cells.

ERK and Akt were involved in RANKL-induced breast cancer cell migration. The downstream signaling of RANKL/ RANK in MCF-7 cells was examined. Since the Akt and ERK pathways were closely correlated with cell invasion and migration (13,14,24-26), the effect of ERK and Akt in the RANKL/ RANK pathway was evaluated. The results showed that sRANKL promoted the activation of ERK and Akt in MCF-7 cells (Fig. 3A). The sRANKL-induced migration was partially blocked with the MEK inhibitor PD98059 $(25 \mu \mathrm{M})$ and the PI3K inhibitor LY294002 (50 $\mu \mathrm{M})$ (Fig. 3B).

These results suggested that the ERK and Akt pathways were involved in RANKL-induced breast cancer cell migration. 
MCF-7

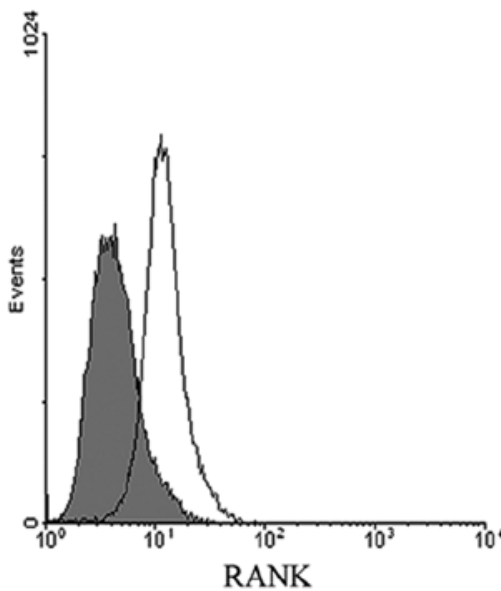

MDA-MB-231

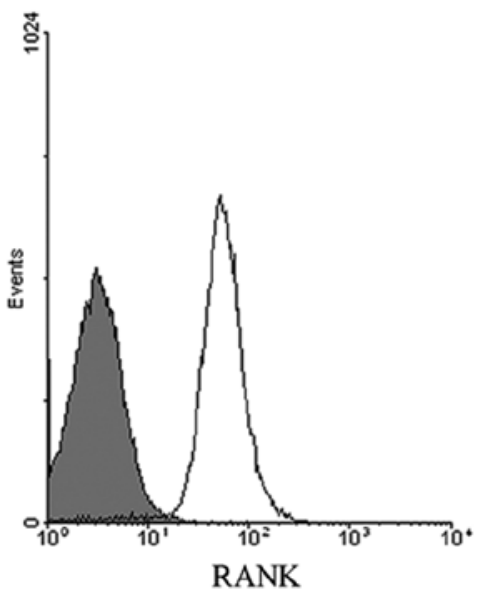

BT-474

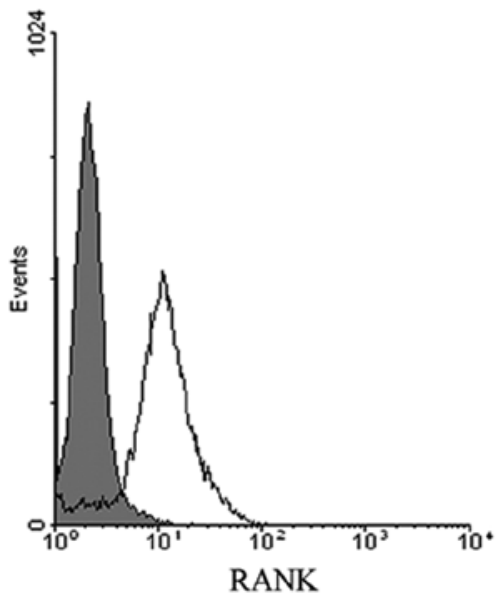

Figure 1. Breast cancer cell lines expressed RANK on their cell surface. RANK expression on the surface of MCF-7, MDA-MB-231 and BT-474 cells was examined by flow cytometry; isotype control staining is shown in grey. RANK, receptor activator for nuclear factor $\mathrm{\kappa B}$.
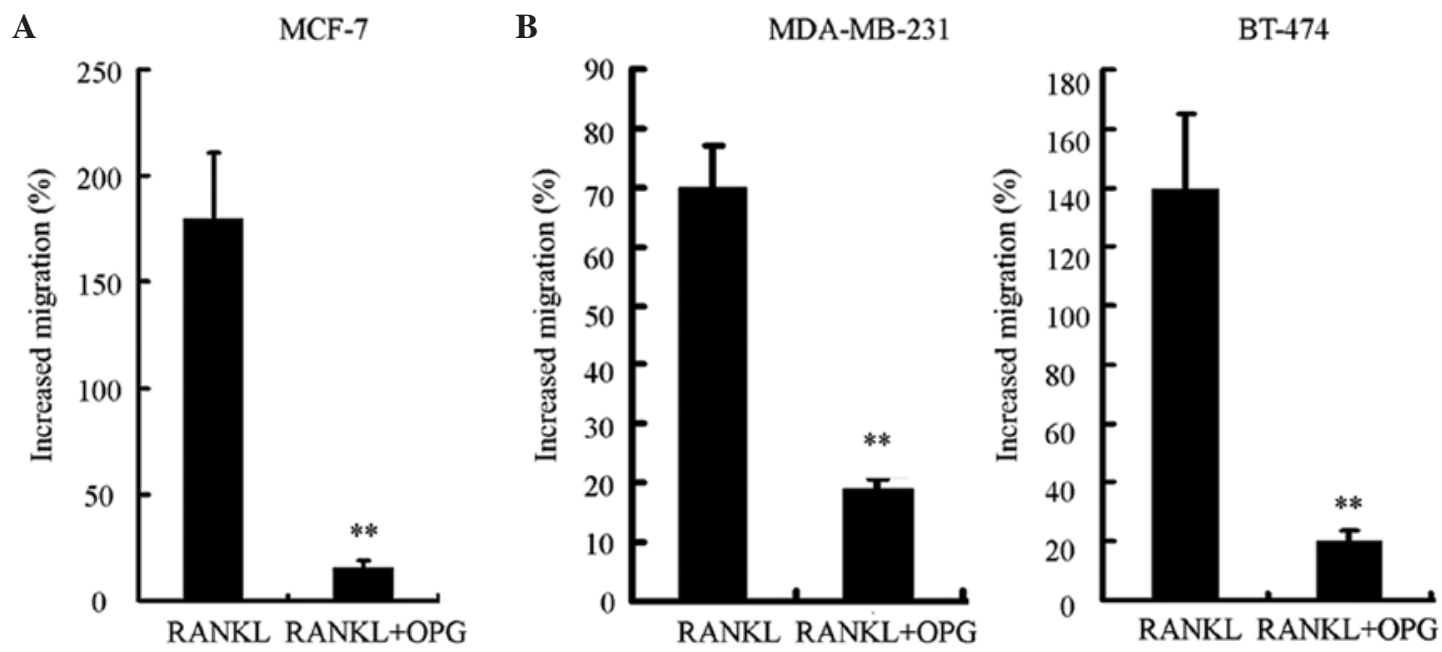

Figure 2. RANKL- and RANK interaction-directed migration of breast cancer cells. (A) MCF-7 cells were incubated with RANKL ( $2 \mu \mathrm{g} / \mathrm{ml})$ with or without rOPG $(10 \mu \mathrm{g} / \mathrm{ml})$, and in vitro migration activity was measured with the Transwell assay after $16 \mathrm{~h}$. (B) MDA-MB-231 and BT-474 cells were incubated with RANKL $(2 \mu \mathrm{g} / \mathrm{ml})$ with or without rOPG $(10 \mu \mathrm{g} / \mathrm{ml})$, separately, and in vitro migration activity was measured with the Transwell assay after $16 \mathrm{~h}$. Results are expressed as the mean $\pm \mathrm{SD}$. The data show the results from at least three independent experiments. ${ }^{* *} \mathrm{P}<0.01$ indicated a significant difference compared with the control. OPG, osteoprotegerin RANKL, receptor activator for nuclear factor $\mathrm{\kappa B}$ ligand; rOPG, recombinant human OPG.

$c$-Src mediated, RANKL-induced breast cancer cell migration through activation of the ERK and Akt pathways. The effect of c-Src in the RANKL/RANK pathway and migration activity in MCF-7 cells was evalutated. Rapid activation of c-Src (Fig. 4A) in MCF-7 cells was observed following treatment with sRANKL for $5 \mathrm{~min}$. In addition, PP2 $(10 \mu \mathrm{M})$, a type of Src family kinase inhibitor, markedly inhibited sRANKL-induced MCF-7 cell migration (Fig. 4B), accompanied with the inhibition of the activation of ERK and Akt (Fig. 4C).

Taken together, these results suggest that c-Src-mediated RANKL-induced breast cancer cell migration occurs through activation of the ERK and Akt pathways.

\section{Discussion}

The RANKL/RANK pathway has emerged as the key pathway in the regulation of osteoclasts and lymphocyte proliferation and survival. RANKL interacts with RANK and, in turn, recruits tumor necrosis factor receptor-associated factors (TRAFs) (27), leading to the activation of $\mathrm{NF}-\kappa \mathrm{B}$, c-Jun N-terminal kinase (JNK), p38, ERK and Akt (28-30). Recent studies (4,12-15) have shown that RANK is also expressed on the surface of certain cancer cells and that RANKL functions as a chemokine and directs RANK-expressing cancer cells to preferentially migrate into bone, which is the crucial and initial step for bone metastasis. However, the manner in which this cytokine is involved in tumor metastasis remains to be elucidated.

Previous studies regarding RANKL/RANK signal pathways have mainly focused on melanoma, lung and prostate cancer cells $(4,13,14)$. In the present study, three representative cell line models for different protein subtypes of breast cancer, MCF-7 (ER/PR $\left.{ }^{+}, \mathrm{Her}-2^{-}\right), \mathrm{BT}-474$ (ER/PR $\left.{ }^{+}, \mathrm{Her}-2^{+}\right)$ and MDA-MB-231 (ER/PR', Her-2 ${ }^{-}$, were used to examine the role of the RANKL/RANK signaling pathway. RANK was 
A

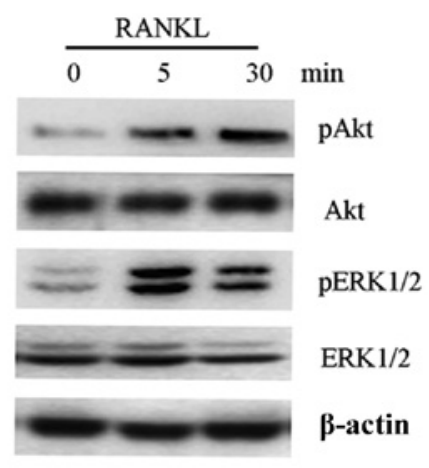

B

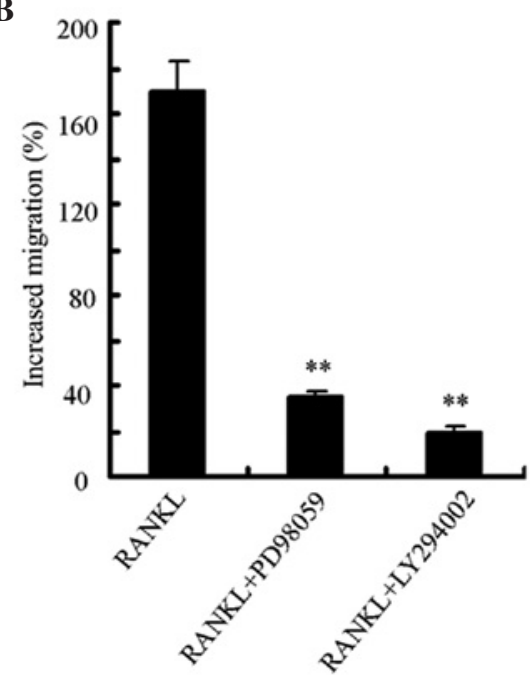

Figure 3. ERK and Akt were involved in RANKL-induced breast cancer cell migration. (A) MCF-7 cells were incubated with sRANKL for the indicated time intervals, and pAkt/Akt, pERK/ERK1/2 and $\beta$-actin were examined by Western blot analysis. (B) MCF-7 cells were incubated with RANKL ( $2 \mu \mathrm{g} / \mathrm{ml})$ with or without LY294002 (50 $\mu \mathrm{M}$, PI3K inhibitor) and PD98059 (25 $\mu \mathrm{M}$, MEK/ERK inhibitor), migration activity was measured with the Transwell assay after $16 \mathrm{~h}$. Results are expressed as the mean $\pm \mathrm{SD}$. The data show the results from at least three independent experiments. ${ }^{* *} \mathrm{P}<0.01$ indicate significant differences compared with the control. RANKL, receptor activator for nuclear factor $\kappa \mathrm{B}$ ligand; sRANKL, soluble receptor activator for nuclear factor $\kappa \mathrm{B}$ ligand.

A

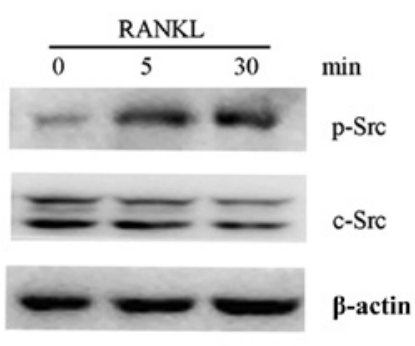

C

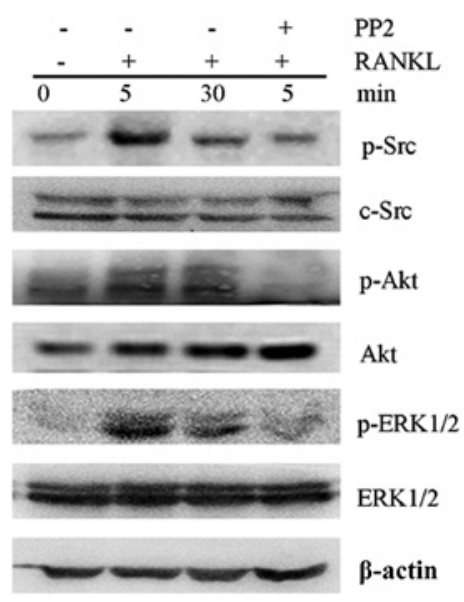

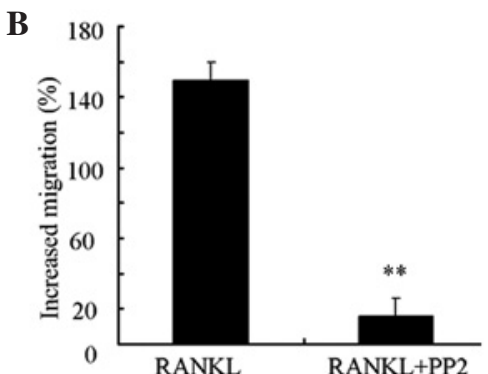

(1)

( sRANKL for the indicated time intervals, and p-Src/c-Src and $\beta$-actin were examined by Western blot analysis. (B) MCF-7 cells were incubated with RANKL $(2 \mu \mathrm{g} / \mathrm{ml})$ with or without PP2 (10 $\mu \mathrm{M}$, c-Src inhibitor); migration activity was measured with the Transwell assay after $16 \mathrm{~h}$. Results are expressed as the mean $\pm \mathrm{SD}$. The data show the results from at least three independent experiments. ${ }^{* *} \mathrm{P}<0.01$ indicate significant difference compared with the control. (C) Following pretreatment with or without PP2 for $1 \mathrm{~h}, \mathrm{MCF}-7$ cells were incubated with sRANKL for indicated time intervals, and p-Src/c-Src, pAkt/Akt, pERK/ERK1/2 and $\beta$-actin were examined by Western blot analysis. RANKL, receptor activator for nuclear factor $\kappa B$ ligand; sRANKL, soluble receptor activator for nuclear factor $\kappa \mathrm{B}$ ligand.

expressed in all three types of breast cancer cells. Moreover, whereas RANKL promoted the migration of breast cancer cells, OPG was able to block the enhanced migration induced by RANKL.
Findings of previous studies have shown that AKT and ERK1/2 were closely correlated with cell migration $(13,14$, 24-26). In mouse B16F10 melanoma cells, pretreatment with the inhibitor of PI3K, PKC, PLC or MEK1/2 suppressed 
RANKL-induced migration (4). In the present study, AKT and ERK1/2 were phosphorylated following RANKL stimulation; although RANKL does not directly affect their proliferation or survival. The result was in accordance with the study by Jones et al in T47D breast cancer cells (4). However, in prostate cancer cell lines, ERK1/2, but not Akt, was involved in RANKL-induced migration $(13,19)$.

Non-receptor tyrosine kinase c-Src was reported to selectively promote bone metastasis $(20,21)$. In the present study, c-Src was involved in RANKL-induced breast cancer cell migration. In addition, PP2, the inhibitor of c-Src, inhibited the activation of ERK1/2 and Akt, suggesting an essential role for c-Src and downstream ERK and Akt in breast cancer cell migration. These results differ from the RANKL/RANK pathway in prostate cancer cells, in which c-Src promoted the activation of ERK1/2 but not AKT (19). Therefore, RANKL/ RANK signaling may vary in different tumor cell types. To the best of our knowledge, this is the first study to show that c-Src may be a key downstream mediator of RANKL-induced migration in breast cancer cells.

A number of studies have examined and confirmed the link between the RANK/RANKL pathway and propensity to metastasize to the bone $(4,12,31)$. Recently, clinical trials with a fully human anti-RANKL antibody, denosumab, have been initiated in patients with prostate and breast cancer bone metastases with promising results $(32,33)$. This antibody had been fast tracked by the US FDA for treatment and prevention of post-menopausal osteoporosis and treatment and prevention of bone loss in hormone-treated prostate and breast cancer patients $(34,35)$. Furthermore, Src inhibitors, including dasatinib, saracatinib and bosutinib, are currently under clinical investigation for patients with solid tumors, as available data show activity in bone (36-39). Our results have shown the direct anti-metastasis effects of RANKL and/or c-Src inhibitors. Therefore, we suggest that the use of Src inhibitors and/or RANKL selective inhibitors may be of therapeutic benefit in breast cancer patients.

\section{Acknowledgements}

We thank our clinical and laboratory colleagues who have contributed to our research. This study was supported by grants from the Chinese National Foundation of National Sciences grants (grant number 30700807) and Science and Technology project of Liaoning Province (grant number 2010225032).

\section{References}

1. Jemal A, Siegel R, Xu J and Ward E: Cancer statistics. CA Cancer J Clin 60: 277-300, 2010.

2. Muller A, Homey B, Soto H, et al: Involvement of chemokine receptors in breast cancer metastasis. Nature 410: 50-56, 2001.

3. Moore MA: The role of chemoattraction in cancer metastases. Bioessays 23: 674-676, 2001.

4. Jones DH, Nakashima T, Sanchez OH, et al: Regulation of cancer cell migration and bone metastasis by RANKL. Nature 440: 692-696, 2006

5. Roodman GD: Mechanisms of bone metastasis. N Engl J Med 350: 1655-1664, 2004.

6. Yasuda H, Shima N, Nakagawa N, et al: Osteoclast differentiation factor is a ligand for osteoprotegerin/osteoclastogenesis-inhibitory factor and is identical to TRANCE/RANKL. Proc Natl Acad Sci USA 95: 3597-3602, 1998.
7. Lacey DL, Timms E, Tan HL, et al: Osteoprotegerin ligand is a cytokine that regulates osteoclast differentiation and activation. Cell 93: 165-176, 1998.

8. Keller ET: The role of osteoclastic activity in prostate cancer skeletal metastases. Drugs Today (Barc) 38: 91-102, 2002.

9. Thomas RJ, Guise TA, Yin JJ, et al: Breast cancer cells interact with osteoblasts to support osteoclast formation. Endocrinology 140: 4451-4458, 1999.

10. Hsu H, Lacey DL, Dunstan CR, et al: Tumor necrosis factor receptor family member RANK mediates osteoclast differentiation and activation induced by osteoprotegerin ligand. Proc Natl Acad Sci USA 96: 3540-3545, 1999.

11. Nakagawa N, Kinosaki M, Yamaguchi K, et al: RANK is the essential signaling receptor for osteoclast differentiation factor in osteoclastogenesis. Biochem Biophys Res Commun 253: 395-400, 1998.

12. Mikami S, Katsube K, Oya M, et al: Increased RANKL expression is related to tumour migration and metastasis of renal cell carcinomas. J Pathol 218: 530-539, 2009.

13. Armstrong AP, Miller RE, Jones JC, Zhang J, Keller ET and Dougall WC: RANKL acts directly on RANK-expressing prostate tumor cells and mediates migration and expression of tumor metastasis genes. Prostate 68: 92-104, 2008.

14. Chen LM, Kuo CH, Lai TY, et al: RANKL increases migration of human lung cancer cells through intercellular adhesion molecule-1 up-regulation. J Cell Biochem 112: 933-941, 2011.

15. Santini D, Perrone G, Roato I, et al: Expression pattern of receptor activator of NFKB (RANK) in a series of primary solid tumors and related bone metastases. J Cell Physiol 226: 780-784, 2011.

16. Hiscox S, Jordan NJ, Morgan L, Green TP and Nicholson RI: Src kinase promotes adhesion-independent activation of FAK and enhances cellular migration in tamoxifen-resistant breast cancer cells. Clin Exp Metastasis 24: 157-167, 2007.

17. Meng XN, Jin Y, Yu Y, et al: Characterisation of fibronectinmediated FAK signalling pathways in lung cancer cell migration and invasion. Br J Cancer 101: 327-334, 2009.

18. Summy JM and Gallick GE: Src family kinases in tumor pro gression and metastasis. Cancer Metastasis Rev 22: 337-358, 2003.

19. Sabbota AL, Kim HRC, Zhe X, Fridman R, Bonfil RD and Cher ML: Shedding of RANKL by tumor-associated MT1-MMP activates Src-dependent prostate cancer cell migration. Cancer Res 70: 5558-5566, 2010.

20. Myoui A, Nishimura R, Williams PJ, et al: c-Src tyrosine kinase activity is associated with tumor colonization in bone and lung in an animal model of human breast cancer metastasis. Cancer Res 63: 5028-5033, 2003.

21. Zhang XH, Wang Q, Gerald W, et al: Latent bone metastasis in breast cancer tied to Src-dependent survival signals. Cancer Cell 16: 67-78, 2009.

22. Riaz M, Elstrodt F, Hollestelle A, Dehghan A, Klijn JG and Schutte M: Low-risk susceptibility alleles in 40 human breast cancer cell lines. BMC Cancer 9: 236, 2009.

23. Kenny P, Lee G, Myers C, et al: The morphologies of breast cancer cell lines in three-dimensional assays correlate with their profiles of gene expression. Mol Oncol 1: 84-96, 2007.

24. Gan Y, Shi C, Inge L, Hibner M, Balducci J and Huang Y: Differential roles of ERK and Akt pathways in regulation of EGFR-mediated signaling and motility in prostate cancer cells. Oncogene 29: 4947-4958, 2010.

25. Jiang Q, Zhou C, Bi Z and Wan Y: EGF-induced cell migration is mediated by ERK and PI3K/AKT pathways in cultured human lens epithelial cells. J Ocul Pharmacol Ther 22: 93-102, 2006.

26. Hwang YP, Yun HJ, Choi JH, et al: Suppression of EGF-induced tumor cell migration and matrix metalloproteinase-9 expression by capsaicin via the inhibition of EGFR-mediated FAK/Akt, PKC/Raf/ERK, p38 MAPK, and AP-1 signaling. Mol Nutr Food Res 55: 594-605, 2011.

27. Darnay BG, Haridas V, Ni J, Moore PA and Aggarwal BB: Characterization of the intracellular domain of receptor activator of NF- $\kappa \mathrm{B}$ (RANK). Interaction with tumor necrosis factor receptor-associated factors and activation of NF- $\mathrm{KB}$ and c-Jun N-terminal kinase. J Biol Chem 273: 20551-20555, 1998

28. Chen $\mathrm{T}$ and Feng X: Cell-based assay strategy for identification of motif-specific RANK signaling pathway inhibitors. Assay Drug Dev Technol 4: 473-482, 2006.

29. Darnay BG,Ni J, Moore PAandAggarwal BB:Activation of NF- $\kappa B$ by RANK requires tumor necrosis factor receptor-associated factor (TRAF) 6 and NF- $\mathrm{kB}$-inducing kinase. Identification of a novel TRAF6 interaction motif. J Biol Chem 274: 7724-7731, 1999. 
30. Lee SY, Reichlin A, Santana A, Sokol KA, Nussenzweig MC and Choi Y: TRAF2 is essential for JNK but not NF- $\kappa B$ activation and regulates lymphocyte proliferation and survival. Immunity 7 : 703-713, 1997.

31. Santini D, Schiavon G, Vincenzi B, et al: Receptor activator of $\mathrm{NF}-\kappa \mathrm{B}$ (RANK) expression in primary tumors associates with bone metastasis occurrence in breast cancer patients. PLoS One 6: e19234, 2011.

32. Fizazi K, Carducci M, Smith M, et al: Denosumab versus zoledronic acid for treatment of bone metastases in men with castration-resistant prostate cancer: a randomised, double-blind study. Lancet 377: 813-822, 2011.

33. Stopeck AT, Lipton A, Body JJ, et al: Denosumab compared with zoledronic acid for the treatment of bone metastases in patients with advanced breast cancer: a randomized, double-blind study. J Clin Oncol 28: 5132-5139, 2010.

34. Lipton A, Steger GG, Figueroa J, et al: Randomized activecontrolled phase II study of denosumab efficacy and safety in patients with breast cancer-related bone metastases. J Clin Oncol 25: 4431-4437, 2007.
35. Rifkin WD: Denosumab in postmenopausal women with low bone mineral density. N Engl J Med 354: 2390-2391; author reply 2390-2391, 2006

36. Onishi T, Hayashi N, Theriault RL, Hortobagyi GN and Ueno NT: Future directions of bone-targeted therapy for metastatic breast cancer. Nat Rev Clin Oncol 7: 641-651, 2010.

37. Mayer EL and Krop IE: Advances in targeting SRC in the treatment of breast cancer and other solid malignancies. Clin Cancer Res 16: 3526-3532, 2010.

38. Araujo J and Logothetis C: Targeting Src signaling in metastatic bone disease. Int J Cancer 124: 1-6, 2009.

39. Saad F and Lipton A: SRC kinase inhibition: targeting bone metastases and tumor growth in prostate and breast cancer. Cancer Treat Rev 36: 177-184, 2010. 